\title{
MICROSONIC RETRIEVABILITY OF INTRACANAL SEPARATED ROTARY NICKEL-TITANIUM INSTRUMENTS HAVING ASYMMETRIC VERSUS SYMMETRIC DESIGNS AND EVALUATION OF REMAINING DENTIN THICKNESS USING CBCT
}

\author{
Ghada El-Hilaly Eid* and Reham Mohammed Saeed Seyam*
}

\begin{abstract}
Objective: This study compared retrievability of two rotary nickel Titanium (NiTi) instruments with symmetric versus asymmetric cross sections; ProTaper Universal ${ }^{\circledR}$ and RevoS $\AA$, respectively, with reference to the influence of some anatomic factors, as well as evaluated of the remaining minimum dentin thickness after retrieval using cone beam computed tomography (CBCT).

Materials and Methods: Thirty six extracted mandibular first molars with curved mesiobuccal canals were used. The apical $4 \mathrm{~mm}$ of ProTaper Universal rotary NiTi instrument $®$ (Dentsply Maillefer, Ballaigues, Switzerland) size F3 ( $\mathrm{n}=18)$ and RevoS rotary NiTi instrument ${ }^{\circledR}$ (MicroMega, Besanc, on, France) size A35/06 ( $n=18)$ were fractured in the apical region of the canal. Fragments were located at apical or apical-middle and their coronal end were before canal curvature, at or beyond it. Microsonic technique was successful when instrument retrieval occurred without mishaps. Post retrieval CBCT was superimposed on preoperative CBCT to determine changes in distal dentin thickness (at coronal end of instrument $(\mathrm{C}$ level) and at furcation level (F level) and in canal width. Chi-square test evaluated success incidence between the two instruments types and effects of influencing anatomic factors. Mann-Whitney U test compared quantitative data, significance was set at $P<0.05$.
\end{abstract}

Results: Overall success rate for removal of fractured fragments was $72.2 \%$ with equal incidence in both instruments types. Retrieval of ProTaper instrument was positively affected by being in the apical-middle location, $P=0.047$. Retrieval of RevoS instrument was positively affected by being before and at the curvature; $P=0.04$. CBCT measurements showed overall minimum distal dentin thickness after retrieval to be approximately $0.67 \pm 0.14 \mathrm{~mm}$. Percent of dentin removal was significantly higher at $F$ level, $P=0.04$, while Canal width was higher at $C$ level $P=0.052$. In ProTaper group, percent of dentin removal at $C$ level was slightly lower than in RevoS group, $P=0.28$. Strip perforation occurred in 8 samples and secondary fracture in 2 samples.

* BDS, MSc, PhD, Associate Professor in Endodontics, Endodontic Department, Faculty of Oral and Dental Medicine, Cairo University, Egypt. 
Conclusions: The successful removal of fractured $\mathrm{Ni}$-Ti instruments is more influenced by anatomical factors namely; the position of the instrument within the root canal, the location of the fractured instrument in relation to the root canal curvature and the remaining dentin thickness. Instrument's design indirectly affects success by requiring greater amount of dentin removal to disengage it.

KEY WORDS: Microsonic instrument removal, rotary NiTi instrument design, separated instruments, CBCT

\section{INTRODUCTION}

Flexibility of NiTi rotary instruments offers advantage in shaping curved canals ${ }^{1}$. There is, however, risk of intracanal instrument separation resulting from torsional overload or flexural cyclic fatigue ${ }^{2,3}$. Generally the fragment fracture at a smaller length, further apically, at or around the curve, and because of their rotational motion, they tend to screw in, get wedged in the canal walls, and occlude the entire canal lumen ${ }^{4,5}$. This can have probable impact on the prognosis of endodontic treatment; especially with compromised cleaning and shaping and if periapical pathology is present at the time of treatment ${ }^{6}$.

Many instruments/devices and techniques have been described for separated instrument retrieval, however, with no precise standardized procedure $^{7-10}$. The mostly approved protocol is the microsonic technique; utilization of the microscope in conjunction with optimally designed ultrasonic instruments ${ }^{5,7,11-16}$. Success rates for the removal of fractured instruments using microsonic technique have been reported to be between $80 \%$ and $91.1 \%$ in laboratory ${ }^{5,13,15,17,18}$, and between $66.6 \%$ and $93 \%$ in clinical studies ${ }^{19-21}$. Varying amount of dentin is removed during gaining access to the obstruction and in removing it ${ }^{5,13,22}$. Excessive enlargement can lead to procedural mishaps; perforation, reduced root strength 15, 17,23, and secondary instrument fracture $11,13,16,18$.

Anatomical and instrument related factors influence safe successful retrieval 7,22,24,25. These include canal anatomy (shape ${ }^{4,24}$, canal curvature ${ }^{9,18,20,24,25}$, root morphology: dentin thickness and the depth of external concavities 9, instrument's fractured length $20,24,25$, site of fracture along the canal length ${ }^{4,8,17,20,22-24}$ and position of the fractured end in relation to canal curvature $5,9,11,20,24,25$.

A potential factor that might also affect incidence of retrievability is the instrument geometrical design 9, 10, 24, 25, which determines its bulk, degree of screwing into the wall and intimacy of contact area between the file and dentin wall 9, 20, 25. Both Protaper Universal ${ }^{\circledR}$ (Dentsply Maillefer, Ballaigues, Switzerland) and RevoS $®$ (Micro-Mega, Besanc son, France) are rotary NiTi instruments having a triangular cross sectional designs ${ }^{26,27}$. RevoS, however, is characterized by asymmetric design that increases its flexibility, and decreases the contact between the file and canal wall; this might provide a space during retrieval of fragments better than with symmetric cross section of ProTaper Universal.

Studies have evaluated the effect of instrument design on resistance to fracture ${ }^{2,10}$, but few addressed the effect of design on successful retrievability of separated instruments. A challenge is encountered attempting to disengage the locked fragment, and spin it out of the canal without sacrificing too much dentin. Thus, the present study compared retrievability of two rotary NiTi instruments with symmetric versus asymmetric cross sections; ProTaper Univeral ${ }^{\circledR}$ and $\operatorname{RevoS}{ }^{\circledR}$, respectively, with reference to the influence of some anatomic factors, as well as evaluation of the remaining minimum dentin thickness after retrieval using cone beam computed tomography CBCT. 


\section{MATERIALS AND METHODS}

\section{1) Selection of teeth and preliminary preparation}

Thirty six extracted mandibular first molars with completely developed curved roots were cleaned, disinfected in $5.25 \% \mathrm{NaOCl}$ for 10 minutes then stored in $0.1 \%$ thymol solution. Conventional access cavities were prepared and the clinical crowns were reduced to standardize tooth length to $17 \pm 1 \mathrm{~mm}$. Mesiobuccal canals were prepared by rotary nickel titanium instrumentation, up to a standard apical size of 30/04 taper (HERO shaper®, Micro-Mega, France). After embedding in resin blocks, teeth were initially scanned (CBCT-Scan I: Preoperative) by cone beam microcomputed tomography scanner (Next Generation i-CAT, imaging Sciences International, Inc., Hatfield, USA) at $120 \mathrm{kVp}, 37.07 \mathrm{mAs}$, and $0.125 \mathrm{~mm}$ voxel size. Data were transferred in DICOM format, where, Invivo Dental software (version 5.1; Anatomage, San Jose, CA, USA) was utilized for angular and linear measurement. Root canal curvature was measured from facial and proximal aspects by Schneider technique ${ }^{28}$. Canals had curvature mean of $25.6^{\circ} \pm 6.7$ ranging from 12.8 to $40.1^{\circ}$. They were classified to moderate $\left(<25^{\circ} \mathrm{n}=16\right)$ or severe $\left(\geq 25^{\circ} \mathrm{n}=20\right)^{18}$.

\section{2) Grouping of samples and intracanal instru- ment's fracture}

The teeth were divided into 2 groups ( $\mathrm{n}=18$ each), according to the type of separated instrument; such that each curvature range was equally assigned to: Group A: RevoS rotary nickel-Titanium instrument (B) size A35(35/06) and group B: ProTaper rotary nickel-Titanium instrument ${ }^{\circledR}$ size F3 (30/09), Figure (1). Instruments were tried by hand-fitting before the separation process to check that they met resistance at approximately $2 \mathrm{~mm}$ short of the working length in the prepared canal.

Instruments were notched to half depth at $4 \mathrm{~mm}$ from the tip using a low speed diamond disc and rotated into the canal at $250 \mathrm{rpm}$ and torque of 2.5
$\mathrm{N} \mathrm{cm}^{-1}$; using electric motor (X smart, Maillefer, Densply). When resistance was felt, pressure was applied until it fractured. Another CBCT was taken after instrument fracture (CBCT-Scan II: Post fracture); to measure the position of the apical end in relation to the working length and categorize location whether exactly at it (apical) or short of it (apical-middle). Also the coronal end of the separated instrument in relation to the canal curve was determined; and further categorizes location whether before canal curvature, at or beyond it. The availability of space around the instrument was also recorded. Minimum dentin thickness on bifurcation side was measured to guide during troughing.

\section{3) Procedure for separated instrument retrieval}

The procedure was set as standardized sequence of steps derived from a blend of two previously described techniques; initially starting as described by Ruddle ${ }^{7}$ and if needed continuing as recommended by Terauchi et al ${ }^{16}$. Adequate magnification and light were provided by a dental operating microscope (Global Surgical, St. Louis, MO). Coronal access was flared on the mesial wall for convenience. Intracanal straight line access to the coronal end of the instrument, was created by Gates Glidden drills no. 2,3 (Mani, Nakaakutsu, Japan) followed by ultrasonic tip ET40D (Satelec/ Acteon, Merignac, France) operating dry at low power setting (4) of ultrasonic device (P5-Newtron; Satelec). Circumferential staging platform at the coronal part of the separated segment, was prepared by modified Gates Glidden drills (no. 2,3) (Mani, Japan).

Ultrasonic troughing and activation were performed by ultrasonic file size 25 and tip ET25 (Satelec/ Acteon, France) such that their length reached the fragment and their diameter passively fit around it without impeding visibility. The selected tip was used intermittently (10 seconds) at low power, in counter-clockwise direction dry troughing around the instrument, and exposing about $1 \mathrm{~mm}$ of it. Dentinal dust was blown away 
by a stream of air from dental unit air-way syringe. At this stage ultrasonic vibration alone or wedging the energized tip between the instrument and canal wall might loosen the instrument and spin it out. If instrument was not retrieved, the canal was filled with EDTA solution (Endo-Solution, Cerkamed, Stalowa Wola, Polska), with ultrasonic pecking in the space created between the fragment and the canal furcation side for 60 second. If still retrieval failed, the groove along the inside canal wall was deepened with re-pecking in presence of EDTA. The process of counterclockwise dry troughing, followed by deepening and pecking in presence of EDTA at the canal furcation side were repeated until fragment retrieval or procedural misshap occurred. The roots were rescanned using CBCT (CBCT-Scan III: Post retrieval).

\section{4) Assessment after instrument retrieval:}

Success of instrument retrieval was recorded when removal of separated instrument occurred without any mishaps. Failure of retrieval was indicated by occurrence of perforation as evident under the operating microscope and confirmed by CBCT or occurrence of irretrievable non visible secondary instrument separation.

Radiographic measurements for teeth with successful retrieval were performed from CBCT scans, (Figure 2). After superimposition of $C B C T$ Scan I: Preoperative and CBCT-Scan III: Post retrieval, using the superimposition module of the Invivo Dental software, the following were measured: First minimum distal dentin thickness before and after retrieval at two levels; bifurcation level (F Level), and at coronal end of separated instrument (C Level), from which percent removal of distal root dentin was calculated $\{$ (dentin thickness before retrieval- dentin thickness after retrieval/ dentin thickness before retrieval) x100\} Second: mesiodistal canal width and the mesiodistal root width after retrieval at the two levels, from which the percent of canal width relative to root width after retrieval was calculated.

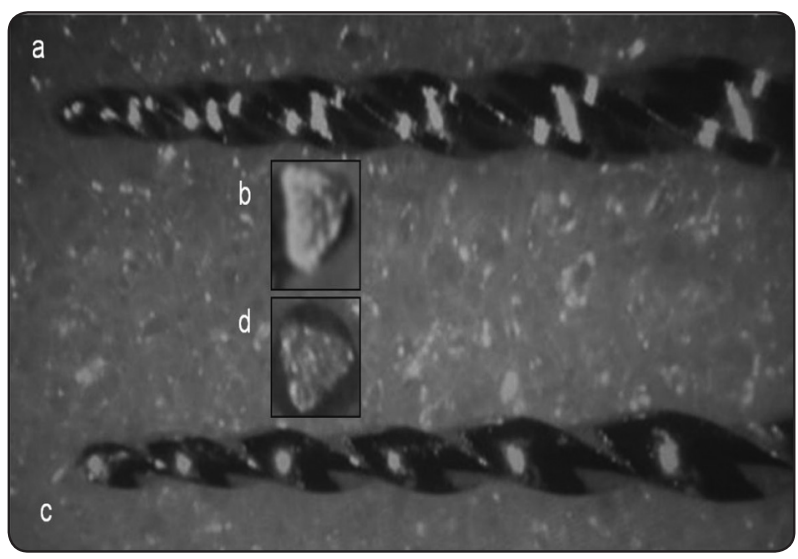

Fig. (1) Stereomicroscopic pictures of ProTaper Universal F3 (a) Lateral view, (b) Cross Section and RevoS size A35

(c) Lateral view, (d) Cross Section

\section{5) Statistical analysis}

Data were tabulated and statistically analyzed using SPSS 18.0 software (SPSS Inc, Chicago,IL). Success of retrieval was described as frequencies and percentages. Chi-square test evaluated success incidence between the two instruments types. Furthermore, the effect of Location along the canal, instrument position in relation to canal curvature, and space availability were evaluated for the overall success and for success within each instrument type. Fisher exact test was used when individual cells showed frequency $<5$. Mann-Whitney $U$ test compared quantitative data related to root dentin thickness and the percent canal width/ root width. Level of significance was set at $P<0.05$.

\section{RESULTS}

\section{1-Incidence of Successful retrieval}

The frequency of successful cases in both instruments types and the effect of influencing factors are presented in Table 1. Considering both instruments; the overall success rate for removal of fractured fragments was $72.2 \%(n=26 / 36)$, with equal incidence in both instruments types, and no statistical significant difference. Instruments located in the apical-middle region revealed significant successful removal compared to those 

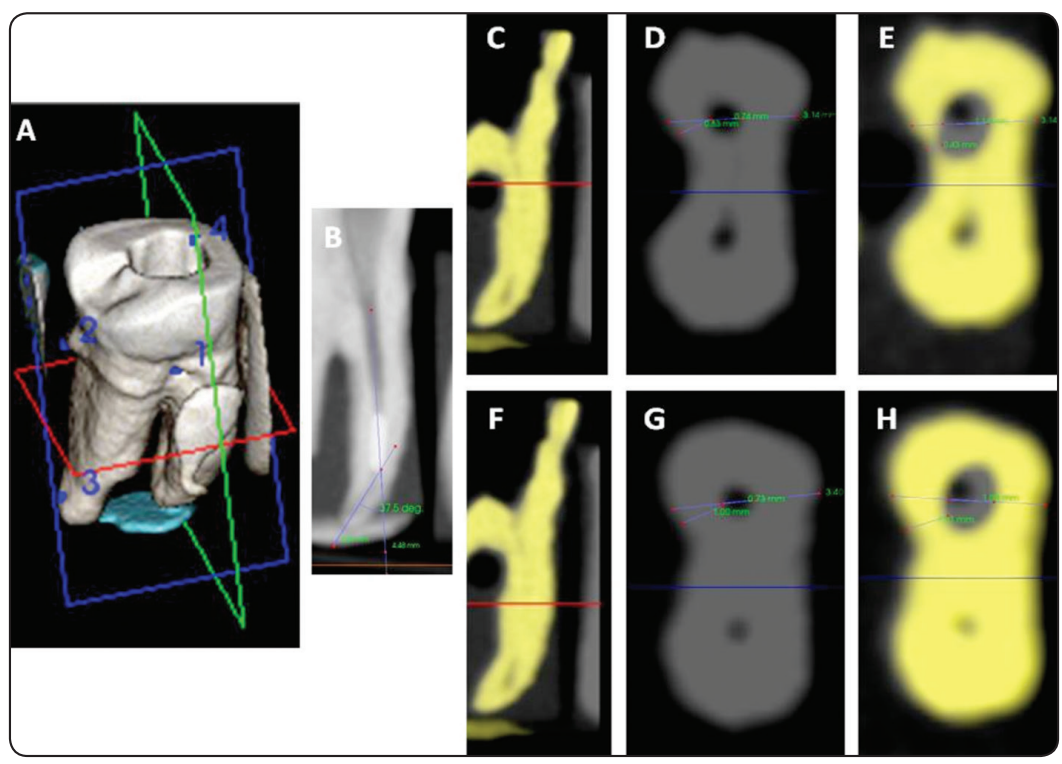

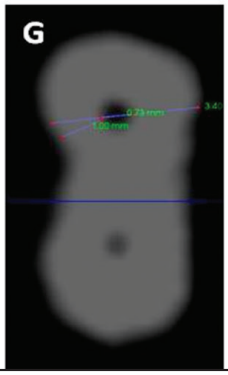

Fig. (2) Steps for CBCT measurements of dentin thickness and canal width. Initially (A) Superimposition module Invivo Dental software was employed to superimpose CBCT-Scan I: Preoperative and CBCT-Scan II: Postfracture for each tooth individually, where four landmarks were chosen at each tooth in both scans then registration of these landmarks was automatically performed by the software. (B) The coronal end of the fractured instrument was determined; hence guaranteeing measuring dentin thickness at the exact level. Then superimposition of CBCT-Scan I: Preoperative and CBCT-Scan III: Post retrieval for (C) Measurement at the furcation level, (D) preoperative and (E) postoperative, of minimum distal dentin thickness, mesiodistal canal width and mesiodistal root width. (F) Measurement at the coronal end of fractured instrument level, $(\mathrm{G})$ preoperative and $(\mathrm{H})$ postoperative, of minimum distal dentin thickness, mesiodistal canal width and mesiodistal root width.

located apically, $P<0.05$. The effect of instrument position in relation to canal curvature showed marginal insignificant difference, $P=0.065$, where instruments before and at the curvature were more successfully retrieved than those located beyond the curve. It was observed that combining these two factors, most fragments in the apical-middle region had their coronal end at or above the curvature, similarly almost all those located beyond the curve were located apically. The influence of canal curvature, and space availability was not statistically significant; $P>0.05$,(Figure 3).

Regarding ProTaper instrument; retrieval success was significantly positively affected by being in the apical-middle location, $P<0.05$, but was not significantly affected by canal curvature, space availability, or by instrument position in relation to canal curvature; $P>0.05$. For RevoS instrument; success of retrieval was significantly affected by instrument position in relation to canal curvature; $P$ $=0.04$, while its retrievability was not significantly affected by location along the canal, canal curvature or space availability; $P>0.05$. Comparing ProTaper versus RevoS instruments on their overall success as well as influence of each factor showed no significant effect; $P>0.05$.

\section{2-CBCT measurements before and after instru- ments retrieval for successful cases (Table 2)}

Considering both instruments; minimum dentin thickness before retrieval was $0.82 \pm 0.17 \mathrm{~mm}$ at $C$ level, and $0.87 \pm 0.16 \mathrm{~mm}$ at $F$ level. While after retrieval it was $0.67 \pm 0.14 \mathrm{~mm}$, and $0.67 \pm 0.15 \mathrm{~mm}$, respectively. Frequency distribution for the overall minimum distal dentin thickness ( $\mathrm{mm}$ ) before retrival and after retrieval is detailed in Figure (4). Comparing dentin removal at $C$ Level and $F$ level: Percent of dentin removal was significantly higher at $F$ level, compared to $C$ level, $P=0.04$. The resulting percent of canal width were approximately $1 / 3$ of root width ; $41 \%$ and $38 \%$ at C Level and $F$ level, respectively, with marginal insignificant difference $P=0.052$.

Each of ProTaper and RevoS showed similarity to the above trend of higher removal of dentin at $F$ level and higher canal width at $C$ level. Comparing ProTaper versus RevoS, no significant difference related to the dentin thickness or canal width at each studied level. However, it was noticed that percent of dentin removal at $C$ level was slightly lower in ProTaper group, $P=0.28$. 


\section{3-Unsuccessful retrieval}

Unsuccessful cases comprised 10/36 (27.8\%) with equal incidence in either instruments. Failure was assigned due to occurance of strip perforation in 8 cases and secondary fracture in 2 cases.

A summary of failures and influencing factors is listed in Table 3. Combining factors together, unsuccessful cases occurred in 10 samples; 7 were located apically (of which five were beyond the curvature and four were with severe curvature). The remaining three were in apical-middle, (of which two were with severe curvature and one was with moderate curve having only $0.3 \mathrm{~mm}$ remaining dentin thickness).

The minimum dentin thickness before retrieval for both instruments was $0.55 \pm 0.19 \mathrm{~mm}$ at $C$ level and $0.88 \pm 0.13 \mathrm{~mm}$ at $F$ level. Stripping occurred at the $\mathrm{C}$ level in all 7 apically positioned cases and it occurred in both $\mathrm{C}$ and $\mathrm{F}$ levels in $4 / 5$ those located apically and beyond the curvature.

TABLE (1) Frequency, percent and statistical comparison of retrieval success according to instrument type and the effect of influencing factors

\begin{tabular}{|c|c|c|c|c|c|}
\hline \multicolumn{2}{|c|}{ Frequency of Success } & $\begin{array}{c}\text { Both Instruments } \\
\text { no. /Total (\%) }\end{array}$ & $\begin{array}{c}\text { ProTaper } \\
\text { no./Total (\%) }\end{array}$ & $\begin{array}{c}\text { RevoS } \\
\text { no./Total }(\%)\end{array}$ & $\begin{array}{c}\begin{array}{c}\text { ProTaper } \\
\text { vs RevoS }\end{array} \\
P \text { value }\end{array}$ \\
\hline \multicolumn{6}{|l|}{ Influencing factors } \\
\hline \multirow[t]{4}{*}{ Location in canal } & Apical-Middle & $19 / 22(86)$ & 10/11 (91) & 9/11(82) & 1 \\
\hline & Apical & $7 / 14(50)$ & $3 / 7(43)$ & $4 / 7(57)$ & 1 \\
\hline & Pvalue & 0.026 & 0.047 & 0.32 & \\
\hline & Before \& At & $21 / 26(80)$ & $9 / 12(\mathbf{7 5})$ & 12/14 (86) & 0.63 \\
\hline \multirow[t]{2}{*}{$\begin{array}{l}\text { Relation of Coronal end of } \\
\text { instrument to canal curvature }\end{array}$} & Beyond & $5 / 10(50)$ & $4 / 6(67)$ & $1 / 4(25)$ & 0.52 \\
\hline & Pvalue & 0.064 & 1 & 0.04 & \\
\hline \multirow[t]{3}{*}{ Canal Curvature } & Moderate & $12 / 16(75)$ & $6 / 8(75)$ & $6 / 8(75)$ & 1 \\
\hline & Severe & $14 / 20(70)$ & $7 / 10(\mathbf{7 0})$ & $7 / 10(\mathbf{7 0})$ & 1 \\
\hline & P value & 1 & 1 & 1 & \\
\hline \multirow[t]{3}{*}{ Space available } & No Space & $17 / 23(74)$ & $10 / 13(\mathbf{7 0})$ & $7 / 10(\mathbf{7 0})$ & 1 \\
\hline & Space & 9/13 (69) & $3 / 5(60)$ & $6 / 8(75)$ & 0.6 \\
\hline & P value & 0.45 & 0.58 & 1 & \\
\hline
\end{tabular}


TABLE (2) Statistical comparison of measurements after retrieval for both instruments and each instrument type at coronal end of instrument (C level), and furcation level (F level)

\begin{tabular}{llcccc}
\hline \multirow{2}{*}{ Measurements after retrieval } & Both instruments & ProTaper & \multicolumn{2}{c}{ RevoS } & ProTaper vs RevoS \\
\cline { 3 - 6 } & & mean \pm SD & mean \pm SD & mean \pm SD & P value \\
\hline Distal min thickness (mm) & C level & $0.67 \pm 0.14$ & $0.66 \pm 0.17$ & $0.67 \pm 0.12$ & 0.8 \\
& F level & $0.67 \pm 0.15$ & $0.63 \pm 0.17$ & $0.71 \pm 0.13$ & 0.9 \\
& $\boldsymbol{P}$ value & 0.82 & 0.47 & 0.57 & \\
Percent removal (\%) & & & & \\
& C level & $15.3 \pm 11.5$ & $12.7 \pm 11.8$ & $17.9 \pm 11$ & $\mathbf{0 . 2 8}$ \\
& F level & $22.26 \pm 11.7$ & $22.4 \pm 14.6$ & $22 \pm 8.3$ & $\mathbf{0 . 7}$ \\
& $\boldsymbol{P}$ value & $\mathbf{0 . 0 4}$ & $\mathbf{0 . 1}$ & $\mathbf{0 . 3 2}$ & \\
& & & & \\
& C level & $41.23 \pm 7.47$ & $41.8 \pm 9.6$ & $40.7 \pm 5$ & $\mathbf{0 . 9 5 9}$ \\
& F level & $38.5 \pm 5.81$ & $39.8 \pm 6.8$ & $37.4 \pm 4.5$ & $\mathbf{0 . 3 3 0}$ \\
& $\boldsymbol{P}$ value & $\mathbf{0 . 0 5 2}$ & $\mathbf{0 . 4 1 1}$ & $\mathbf{0 . 0 6}$ & \\
\hline
\end{tabular}

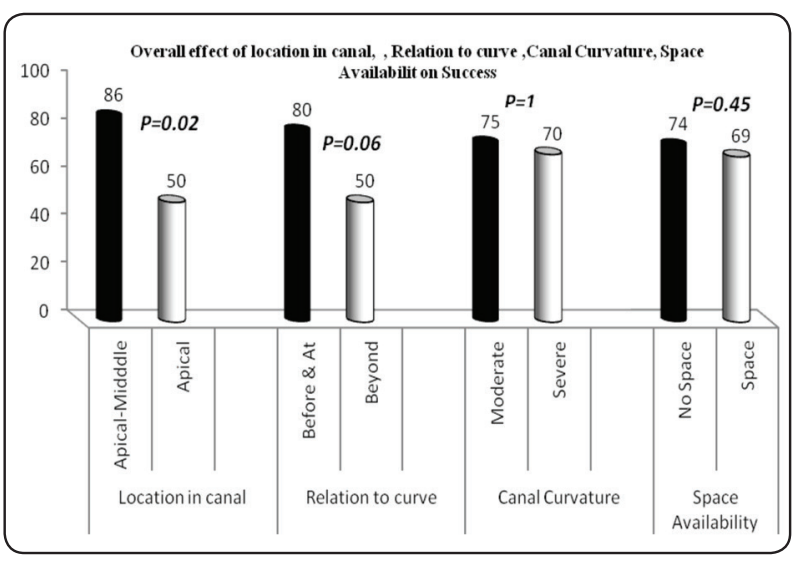

Fig. (3) Percent of success and statistical comparison of the effects of location in canal (Apical-Middle vs Apical), postion in relation to the curve (Before \& At vs beyond) canal curvatures (moderate vs severe), space availability (no space vs space)

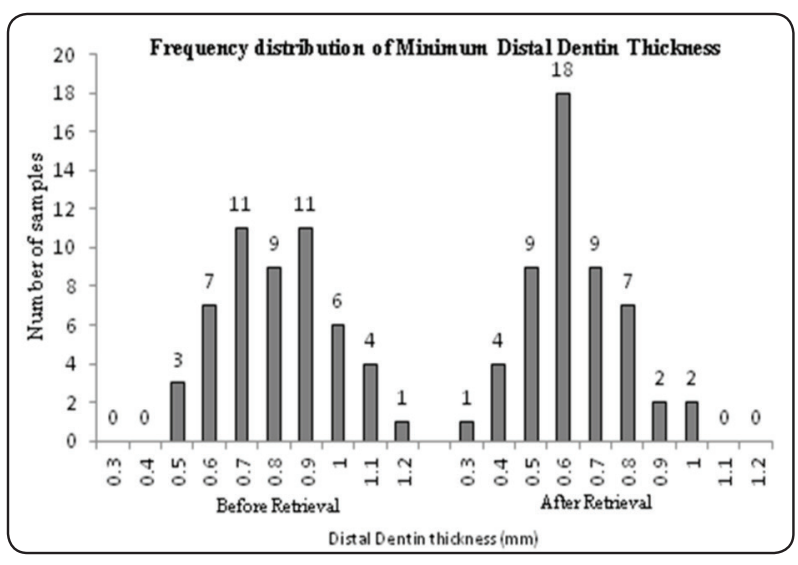

Fig. (4) Frequency distribution for the overall minimum distal dentin thickness $(\mathrm{mm})$ befor retrival and after retrieval 
TABLE (3) Frequency of failure cases according to instrument type and the effect of influencing factors

\begin{tabular}{lcccc}
\hline \multicolumn{1}{c}{ Frequency of failed cases } & Both Instruments & ProTaper & RevoS \\
\cline { 2 - 4 } Generally & & no. /Total (\%) & no/Total (\%) & no./Total (\%) \\
Influencing factors & $\mathbf{1 0 / 3 6 ( 2 7 . 8 )}$ & $5 / 18(27.8)$ & $5 / 18(27.8)$ \\
Location in canal & Apical-Middle & $\mathbf{3 / 1 0}(\mathbf{3 0})$ & $1 / 5(20)$ & $2 / 5(40)$ \\
& Apical & $\mathbf{7 / 1 0}(\mathbf{7 0})$ & $4 / 5(80)$ & $3 / 5(60)$ \\
& & & & \\
Relation of Coronal end of & Before \& At & $\mathbf{5 / 1 0}(\mathbf{5 0})$ & $3 / 5(\mathbf{6 0})$ & $2 / 5(\mathbf{4 0})$ \\
instrument to canal curvature & Beyond & $\mathbf{5 / 1 0}(\mathbf{5 0})$ & $2 / 5(\mathbf{4 0})$ & $3 / 5(\mathbf{6 0})$ \\
& & & & \\
Canal Curvature & Moderate & $\mathbf{4 / 1 0}(\mathbf{4 0})$ & $3 / 5(\mathbf{6 0})$ & $3 / 5(\mathbf{6 0})$ \\
& Severe & $\mathbf{6 / 1 0}(\mathbf{6 0})$ & $2 / 5(\mathbf{4 0})$ & $2 / 5(\mathbf{4 0})$ \\
Space available & & & $2 / 5(\mathbf{4 0})$ & $2 / 5(\mathbf{4 0})$ \\
& No Space & $\mathbf{6 / 1 0}(\mathbf{6 0})$ & $3 / 5(\mathbf{6 0})$ & $3 / 5(\mathbf{6 0})$ \\
\hline
\end{tabular}

\section{DISCUSSION}

Literature reviewing success of retrieval of separated instruments has stated the effect of instrument design as one of the factors affecting its retrieval ${ }^{9,10}$.Up to date, no in-vitro comparative study addressed the influence of this factor on different rotary nickel titanium instruments. Thus it was worthy to evaluate the effect of the cross sectional design and symmetry on success of retrievability of separated rotary NiTi instruments and the amount of dentin sacrificed during microsonic removal in curved canals.

Instrument with sharp cutting edges may increase the degree of engagement into canal wall at the time of separation. Cross sectional shape can affect fitting to canal wall and availability of space lateral to the instrument for ultrasonic tip activation. Both ProTaper and Revo-S systems have triangular cross sectional designs, but large sizes in Protaper Universal version has symmetric triangular concave shape with a shallow U-shaped groove and deep cutting flutes ${ }^{27}$. While Revo-S has smaller asymmetrical triangular cross-section, with three sharp cutting edges located on three different radii; thereby decreasing the contact with canal wall ${ }^{26}$. This asymmetry is hypothesized to provide a space during retrieval of fragments better than those with symmetric cross section. Two probable master apical sizes were studied; F3 of Protaper universal (\#30/9\% in apical 5mm), which is reported to have highest separation incidence ${ }^{27,29}$ and size $35 / 6 \%$ of RevoS which approximates the diameter of F3 at the apical $2 \mathrm{~mm}$. In fact, rotary files with larger diameter are reported to be inflexible and more prone for the dilemma of sudden fracture due to flexural cyclic fatigue ${ }^{27}$.

Based on previous literature, intentional instrument separation was done in mesiobuccal root canal of mandibular molars. These canals are frequently small and curved in three dimensions ${ }^{5,11,24,27,29,30}$. The frequency of $\mathrm{Ni}-\mathrm{Ti}$ instruments fracture is three times higher for the mesio-buccal than mesio-lingual canals ${ }^{31}$ especially in curvature greater than $25^{27}$. 
In the present study, fragments retrieval was directed to short ones of 4-mm length ${ }^{22,23}$ which would present more challenge in removal ${ }^{24,25}$. Efforts were made to fracture all files by applying similar torque and rotation speed ${ }^{22}$. Some files separated at the exact working length and were categorized as "apical", and others fractured just as the instrument was rotating around canal curvature resulting in a position short of the working length and categorized as "apical- middle".

The removal of separated NiTi instruments that lies partially around a canal curvature is a challenge for clinicians because these fragments tend to engage outside the wall of a curved canal $7,16,18$. Assessment of the effect of fragment location on success was done in 2 aspects first: its apical position along the canal length and second: the relation of coronal end of the fragment in relation to the canal curvature ${ }^{10}$. A major limiting factor is the retrieval of deeply located instruments beyond curvature. This is related to the challenge to prepare straight-line access and to visualize the coronal aspect of the fractured instrument segment without sacrificing more dentin ${ }^{18,22,25}$.

CBCT imaging was preferred over the twodimensional traditional radiographs because of its ability to view three-dimensional structures ${ }^{22}$. CBCT images were useful adjunct to assess post fracture apical and coronal position of the instrument, to preoperatively evaluate the relative amount of surrounding dentin and the risk of perforation as well as in evaluating post retrieval changes of root canal space and minimum dentin thickness.

In the present study, the microsonic technique was utilized, which was shown to be predictable in fractured instrument removal ${ }^{5,7,13,17,20}$. To obtain direct access to separated instrument, it was recommended that the canal should be enlarged to at least $0.2 \mathrm{~mm}$ larger in diameter than the separated file but less than $1.0 \mathrm{~mm}$ to avoid strip perforation ${ }^{32}$. The coronal end of the separated instrument measured approximately $0.59 \mathrm{~mm}, 0.66$ $\mathrm{mm}$ at $4 \mathrm{~mm}$ from the tip of RevoS and ProTaper; respectively. Therefore in the present study, only Gates Glidden size 2,3 (\#70,\#90) were used. For troughing both ultrasonic files and tips were used. The ultrasonic tips cut with their ends only resulting in better control on dentin removal. Yet ultrasonic Files are more cost effective, versatile and could be pre-bent easier than ultrasonic tips ${ }^{11}$.

Ultrasonic application combined protocols derived from several reports $5,7,16$. Initially working in dry condition aimed to improve visibility for troughing around the fragment and exposing its coronal end 7 . Further trial, if needed, was resumed in wet condition, EDTA, with pecking on the inner side of the curve ${ }^{36}$. Presence of EDTA served to cool the heat generated and the resultant cavitation with acoustic streaming facilitated file removal. The pecking force applied on the inner side of the curve has resultant coronally directed force on the fragment ${ }^{16}$. Ultrasonic activation was done intermittently at low power to reduce temperature rise ${ }^{33}$.

Some clinical studies defined success by removal or bypassing of fractured instruments with reported success of $53 \%$ to $70.5 \%{ }^{24,25,34}$. However, the present study limited success to sole retrieval because clinically canal infection associated with a retained instrument fragment might compromise prognosis ${ }^{6}$. The overall success rate of the current study $(72 \%$,) was slightly lower than the range reported by many in vitro $(80 \%$ to $93.3 \%) 5,13,15,17,18$ and in vivo studies (66.6\% to $93 \%)^{17,19,20,21}$ which utilized the microsonic technique. In some invitro studies, specimens in which the fragment could not be visualized, removal attempts were abandoned which may be the cause of their increased success 5 , ${ }^{15,17}$, however, in the present study even the invisible fragments were attempted which may account for reduced percent.

The present result indicated that the chance of removing ProTaper fragment was equal to that of 
removing RevoS rotary NiTi instruments. No up-todate in vitro studies specifically addressed the effect of different NiTi instrument design on retrieval, thus no direct comparison could be achieved. However, some comparative data were mentioned in clinical studies ${ }^{20,25}$. It was shown that removing or by passing a hand NiTi K-file fragment with triangular cross-section and traditional 0.02 taper was somewhat higher $(60 \%)$ than rotary ProFile (41\%) with cross-sectional configuration consisting of 3 "radial lands," U-shaped flutes, and noncutting pilot tip and increased body taper ${ }^{25}$. It was reported that success of microsonic technique in retrieval ProFile, ProTaper and FlexMaster rotary NiTi instruments, was $95 \%, 89 \%$ and $86 \%$, respectively ${ }^{20}$. Some In-vitro studies testing retrievability of rotary NiTi or complications associated with it utilized single instrument as Profile sizes $25,4 \%{ }^{5}, 35,4 \%{ }^{17}$, $25,6 \%{ }^{18}$, with reported success in molars of $86.6 \%, 91 \%, 80 \%$ respectively, also Hero shaper size $30,4 \%$ had success of $80 \%{ }^{15}$.

The results of present study confirmed better prognosis for retrieval of fragments that are visualized and not deeply located. Instruments located in the apical-middle region with their coronal end located at or above the canal curvature had increase in successful removal reaching $86 \%$, $80 \%$, respectively. This trend was also revealed in several studies $4,8,15,17,20,24,34$. Even $100 \%$ success was reported ${ }^{17,22}$.

On the other hand, apically lodged segments, especially with the coronal end of the instrument beyond canal curvature, negatively affected retrievability. Deep apically located instruments limit intraradicular targeted application of ultrasonically activated instruments. The inability to see the instrument and the difficulty of creating a staging platform and using ultrasonics around a curve contribute to the lack of success of removing fractured instruments ${ }^{35}$. Greater amount of dentin is removed to visualize the fractured segment beyond the curvature. In the present study, only $50 \%$ of instruments fractured apically and beyond the curve could be removed. Previous studies have also revealed that removal rates are low for fragments that are located apical to the curvature ranging from $31 \%$ to $50 \%{ }^{8,15,19,24,25,34}$.

Looking to the bright side, the present study showed 50\% successful retrieval for separated instruments that lie partially around canal curvatures. Although more difficult, but careful straight line access can be established to their most coronal extents guided by the microcomputed tomography scanning to ascertain the relative amount of surrounding dentin ${ }^{7,19}$.

The present study showed no significant influence of severity of curvature or existence of space on the overall success. This is not in line with several clinical studies that showed increasing retrieval difficulty with increase in canal curvature $17,20,24,25$ and that it is easier to remove fragments from irregularly shaped root canals ${ }^{4}$. This may be due to overlapping factors; where in some cases the presence of isthmus between mesial canals, although mostly moderately or even severely curved, allowed insertion of the tip of the ultrasonic tip alongside the fragment increasing retrieval chance ${ }^{24}$. On the other hand, eventhough a space might exist, if the fragment was locked tightly against the dentin wall of a root canal (wedged), this would increase its retrieval difficulty ${ }^{4}$.

Measurement of remaining dentin wall thickness and canal space width after fractured-instrument removal were important to evaluate the potential hazards of the file removal procedure which included perforation and root weakening ${ }^{5}$. It was suggested that having 0.2 to $0.3 \mathrm{~mm}$ of remaining dentin thickness would place $36 \%$ of the cases in danger of perforating the furcal wall of the root during obturation ${ }^{36}$. This was confirmed in a Finite element study where under simulated lateral compaction models with remaining thickness of 0.42 and 0.32 (having \% of canal width / total root width of $60-70 \%$, respectively), revealed higher 
stresses than those with remaining thickness of 0.65 and $0.75 \mathrm{~mm}$ (representing 40 and $30 \%$ models, respectively) ${ }^{37}$. In the present study the mean minimum dentin thickness before retrieval was $0.84 \pm 0.17 \mathrm{~mm}$, ranging from 0.5 to $1.24 \mathrm{~mm}$ as similarly reported ${ }^{5,22}$. For post retrieval it was $0.67 \pm 0.18 \mathrm{~mm}$, ranging from 0.3 to $1.1 \mathrm{~mm}$ where only five samples fell in the dangerous limit of 0.3$0.4 \mathrm{~mm}$ necessitating care to reduce loading during afterwards obturation or restoration. Nine samples had a borderline safety of $0.5 \mathrm{~mm}$ thickness, and the rest were 0.6 or more. The resultant post retrieval canal width was more at the $\mathrm{C}$ level than $\mathrm{F}$ level, $41.23 \pm 7.4 \%$ and $38.5 \pm 5.81$, respectively, falling within the lower border of safe limit ${ }^{37}$. It might be useful to recommend using the CBCT in measuring the remaining dentin thickness and maximum canal width before attempting any final obturation or restoration after the retrieval procedure.

In the current study more dentin removal was recorded at the bifurcation level than at the coronal end of the instrument; this was necessary during the initial process of achieving better straight line access and visualization. Fortunately, post retrieval remaining dentin thickness was the same at both levels, which reflects the greater thickness at the bifurcation level ${ }^{5,23}$. It was observed that RevoS required more dentin removal at the $\mathrm{C}$ level than ProTaper though not significantly different, and was less successfully retrieved when lodged beyond curvature which can be attributed to its sharper cutting edges that get locked in the canal wall and required more dentin removal for its unlocking.

Strip perforation is a common reported mishap during instrument-removal procedure; $5.7 \%$ to $13 \% 5,13,15,17,24,25$. The present study showed $22 \%$ of 36 cases with strip perforations. Though this might seem a high rate but $70 \%$ of which occurred in apically lodged instruments especially beyond curvatures, where greater dentin removal is required to obtain straight-line access and to disengage the file from the canal wall ${ }^{12,17}$. In the failure cases stripping occurred at the $\mathrm{C}$ level in all 7 apically positioned cases and it occurred in both $\mathrm{C}$ and $\mathrm{F}$ levels in $4 / 5$ of those located apically and beyond the curvature. In some instances during the process of this study a wedged separated instrument would not come out despite successful troughing around its coronal end. In such situation increased troughing as well as dentin cutting for visualization led to perforations ${ }^{38}$.

Secondary instrument fracture also occurred in two RevoS instruments. This mishap was similarly reported $4,11,13,16,18$, overapplication of ultrasonic vibration to the file could be the cause of secondary fracture ${ }^{15}$. Similar to a previous report, one file fragment was also apically extruded ${ }^{4,13}$. A further concern during use of ultrasonic is the development of micro cracks and craze line which may contribute to future fracture ${ }^{15,23}$. The degree and types of developing cracks after ultrasonic retrieval is still worth investigation.

Though both instruments have similar success rates, but observation of the failure group revealed better understanding of the indirect effect of instrument design on unsuccessful retrieval. RevoS presented greater difficulty in apical cases particularly beyond the curvature, underwent two secondary fractures, and required more dentin removal at the coronal end during troughing. Possibly the small triangular cross section and increase instrument flexibility caused the fractured end to lie more on the outside of the canal limiting its outward springing. It has sharp cutting edges that locked the instrument in the canal and required more dentin cutting for its disengaging. On the other hand, ProTaper has greater taper and core metal that resisted secondary fracture, and due to the shallow $U$ shape modification, its cutting edges were not as sharp as in RevoS and did not undergo much engagement in canal walls.

Careful observation of failure cases shows that the highest challenge lies in combinations of four factors: the apical location of the instrument, 
and being beyond canal curvature, together with insufficient dentin thickness to allow troughing around an instrument that has sharply cutting edges deeply locked in dentin. Some clinical recommendation can be suggested regarding the sequence for assessment of the difficulty in retrievability; First: Deep location of the instrument, Second: position in relation to curvature, Third: the thickness of dentin wall, fourth: factors that require more dentin removal such as instrument design and severity of curvature.

Some in vitro studies recommended not to routinely attempt to remove fragments from deep locations because the procedure significantly reduced root strength and increased the risk of root vertical fracture 7, 11,13, 17,23. Alternative technique in conjugation with ultrasonic such as loop or microtube retrieval method was suggested especially when the instrument get loose but can not be retrieved ${ }^{7}$. Other options include obturation up to the fragment. In the presence of signs or symptoms, apical surgery, intentional replantation, or extraction can be considered. It is strictly advised that efforts should be taken to prevent inadvertent fracture of root canal instruments during endodontic treatment ${ }^{4}$.

It should be taken into consideration that experimental studies cannot replicate the clinical situation exactly as instruments have to be separated deliberately, which may result in a different kind and degree of binding inside the root canal. Therefore, success rate of the ultrasonic technique and procedural errors in clinical setting may be different.

From clinical point of view, in a retrospective study ${ }^{14}, 84.4 \%$ survival rate up to 5 -year observation period after microsonic retrieval of separated file was reported. This was attributed to little sacrifice of dentin and proper strengthening by restoration. Further randomized control studies to determine effect of ultrasonic application in the deep parts of the canal on final tooth survival are needed.

\section{CONCLUSIONS}

The successful removal of fractured NiTi instruments is more influenced by anatomical factors namely; the position of the instrument within the root canal, the location of the fragment in relation to canal curvature and the remaining dentin thickness. Instrument's design indirectly affects success especially when its cutting edge is deeply locked in canal wall; requiring greater amount of dentin removal to disengage it. By carefully studying CBCT images, valuable hints can be driven for the clinician to balance chances of success against potential complications and inform patient preoperatively on the presumed treatment outcome and possible treatment risks.

\section{REFERENCES}

1. Thompson SA. An overview of nickel-titanium alloys used in dentistry. Int Endod J 2000;33:297-310

2. Parashos P, Messer HH. Rotary NiTi instrument fracture and its consequences. J Endod 2006; 32: 1031-1043.

3. Cheung GSP. Instrument fracture: mechanisms, removal of fragments, and clinical outcomes. Endod Topics 2007;16: $1-26$.

4. Nagai O,Tani N, Kayaba Y, Kodama S, Osada T. Ultrasonic removal of broken instruments in root canals. Int Endod $\mathrm{J}$ 1986;19: 298-304.

5. Ward, JR., Parashos P, Messer HH. Evaluation of an ultrasonic technique to remove fractured rotary nickeltitanium endodontic instruments from root canals: an experimental study. J Endod 2003; 29:756-763.

6. Panitvisai P, Parunnit P, Sathorn C, Messer HH. Impact of a retained instrument on treatment outcome: a systematic review and meta-analysis. J Endod 2010; 36: 775-780.

7. Ruddle, CJ. Nonsurgical retreatment. J Endod 2004;30: $827-845$.

8. Gencoglu N, Helvacioglu D. Comparison of the different techniques to remove fractured endodontic instruments from root canal systems. Europ J of Dent 2009;3: 90-95.

9. Prateek J, Ganesh B, Aditaya S, Mithra H. Management options of intracanal separated instruments: A review. JPSI 2013;6:17-21

10. Madarati AA, Hunter MJ, Dummer PMH. Management of intracanal separated instruments. J Endod 2013;39: 569-581. 
11. Suter B, Lussi A, Sequeira P. Probability of removing fractured instruments from root canals. Int Endod J 2005; 38:112-123.

12. Terauchi Y, O’Leary L, Suda H. Removal of separated files from root canals with a new file-removal system: case reports. J Endod 2006; 32:789-797.

13. Terauchi Y, O’Leary L, Kikuchi I, Asanagi M, Yoshioka T, Kobayashi C, Suda H. Evaluation of the efficiency of a new file removal system in comparison with two conventional systems. J Endod 2007; 33: 585-588.

14. Fu M, Zhang Z, Hou B. Removal of broken files from root canals by using ultrasonic techniques combined with dental microscope: a retrospective analysis of treatment outcome. J Endod 2011;37: 619-622.

15. Shahabinejad H, Ghassemi A, Pishbin L, Shahravan A. Success of ultrasonic technique in removing fractured rotary nickel-titanium endodontic instruments from root canals and its effect on the required force for root fracture. J Endod 2013;39: 824-828.

16. Terauchi, Yoshitsugu, O'Leary L, Yoshioka T, Suda H. Comparison of the Time Required to Create Secondary Fracture of Separated File Fragments by Using Ultrasonic Vibration under Various Canal Conditions. J Endod 2013;39: 1300-1305.

17. Souter NJ, Messer HH. Complications associated with fractured file removal using an ultrasonic technique. J Endod 2005; 31: 450-452.

18. Alomairy KH. Evaluating two techniques on removal of fractured rotary nickel-titanium endodontic instruments from root canals: an in vitro study. J Endod 2009;35:559562.

19. Ward, JR., Parashos P, Messer HH. Evaluation of an Ultrasonic Technique to Remove Fractured Rotary NickelTitanium Endodontic Instruments from Root Canals: Clinical Cases. J Endod 2003; 29:764-767.

20. Cujé J, Bargholz C, Hülsmann M. The outcome of retained instrument removal in a specialist practice. Int Endod $\mathrm{J}$ 2010; 43, 545-554.

21. Shiyakov KK, Vasileva RI. Success for removing or bypassing instru-ments fractured beyond the root canal curve - 45 clincal cases. J of IMAB, 2014 JulSep;20(3):567-57.

22. Madarati AA, Qualtrough AJE Watts DC.A microcomputed tomography scanning study of root canal space: changes after the ultrasonic removal of fractured files. J Endod 2009;35: 125-128.
23. Madarati AA, Qualtrough AJE, Watts DC. Vertical fracture resistance of roots after ultrasonic removal of fractured instruments. Int Endod J 2010; 43: 424-429.

24. Hülsmann M, Schinkel I. Influence of several factors on the success or failure of removal of fractured instruments from the root canal. Endod Dent Traumatol 1999; 15: 252-258.

25. Shen, Y, Peng B, Cheung GS. Factors associated with the removal of fractured NiTi instruments from root canal systems. Oral Surg, Oral Med, Oral Path, Oral Radiol, Endod 2004; 98: 605-610.

26. http://micro-mega.com/en/wp-content/uploads/2012/10/ MMRevo-S_brochure.

27. Wu J, Lei G, Yan M, Yu Y, Yu J, Zhang G. Instrument Separation Analysis of Multi-used ProTaper Universal Rotary System during Root Canal Therapy. J Endod 2011;37:758-763.

28. Schneider SS. A comparison of canal preparations in straight and curved root canals. Oral Surg Oral Med Oral Pathol 1971;32: 271-275.

29. Wolcott S, Wolcott J, Ishley D, Kennedy W, Johnson S, Minnich S, Meyers J. Separation incidence of Protaper rotary instruments: A large cohort clinical evaluation. J Endod 2006;32:1139-1141.

30. Ungerechts C, Bardsen A, Fristad I. Instrument fracture in root canals - where, why, when and what? A study from a student clinic. Int Endod J, 2014; 47, 183-190.

31. Iqbal MK, Kohli MR, Kim JS A retrospective clinical study of incidence of root canal instrument separation in an endodontics graduate program: a PennEndo database study. J Endod 2006; 32, 1048-52.

32. http://www.dentistrytoday.com/endodontics/7322separate dfileremoval?tmpl=component $\&$ print $=1 \&$ page access on 1 December 2015

33. Madarati AA., Qualtrough AJE, Watts DC. Efficiency of a newly designed ultrasonic unit and tips in reducing temperature rise on root surface during the removal of fractured files. J Endod 2009;35: 896-899.

34. Nevares G, Cunha RS, Zuolo ML, da Silveira Bueno $\mathrm{CE}$. Success rates for removing or bypassing fractured instruments: a prospective clinical study. J Endod 2012; 38: 442-444.

35. Iqbal MK, Rafailov H, Kratchman SI, Karabucak B. A comparison of three methods for preparing centered platforms around separated instruments in curved canals. $\mathrm{J}$ Endod 2006 32, 48-51. 
36. Lim SS, Stock CJ. The risk of perforation in the curved canal: anticurvature filing compared with the stepback technique. Int Endod J 1987;20:33-9.

37. Eid G E. A finite element analysis for the influence of two intraradicular preparation techniques on the stress distribution generated during cold lateral condensation of guttapercha. [PhD thesis]. Cairo University, Faculty of oral and dental medicine, Cairo, Egypt, 2004

38. Okiji T. Modified usage of the Masserann kit for removing intracanal broken instruments. J Endod 2003; 29: 466-467. 